\title{
SPECIAL STRIP PROCESSING EQUIPMENT EFFICIENCY BOOST OF YOUR PROCESSING LINES*
}

\author{
Francisco Morganti ${ }^{1}$ \\ Wilbert Stoy ${ }^{2}$ \\ Fritz Brüh/ ${ }^{3}$ \\ Markus Jaenecke ${ }^{4}$ \\ Caesar Sasse ${ }^{5}$
}

\begin{abstract}
The market requirements which strip processing lines have to deal with have altered significantly within the last decades. Particularly, the production has to be economical and ecological efficient and processing lines have to cover a broad product portfolio. Already existing plants either directly or indirectly are competing with new plants, which are equipped with the latest technologies. The "Special Strip Processing Equipment" is designed to be integrated easily and within small downtime phases in existing lines. All single machines can be delivered in short time "ready-to-perform" with a tested and proved automation system. Thus, the competitiveness of existing lines can be increased immediately with less effort. To find out which machines can be reasonably implemented SMS group offers an "Efficiency Check". A special proceeding is used by experts to find out quickly which machines will have the largest effect on the efficiency of the line while demanding at the same time the smallest expense.
\end{abstract}

Keywords: Strip processing lines; Modernization; Revamps.

1 Dr.-Ing. Metallurgy, Executive Vice Presidient, Strip Processing Lines and Furnace Technology, SMS group, Düsseldorf, Germany.

2 Dipl.-Ing. Machine Engineering, Project Director Sales, Strip Processing Lines and Furnace Technology, SMS group, Hilden, Germany.

3 Technical Communications M.A., Technical Marketing Manager, Strip Processing Lines and Furnace Technology, SMS group, Hilden, Germany. 


\section{INTRODUCTION}

"Special Strip Processing Equipment" increases the efficiency of existing strip processing lines with low amounts of time and cost to be spent for their integration.

\section{CONCEPT}

The demands on the economic and ecological efficiency of strip processing lines have grown. At high productivity, these lines must come with efficient processes and simultaneously cover a wide product range. Existing plants are in competition with new ones. Standardized "Special Strip Processing Equipment" from SMS group is designed to permit easy installation into existing strip processing lines within a short downtime. All machines are supplied in a ready-to-operate condition and with integrated automation system. Thus the competitiveness of existing lines can be increased immediately with less effort.

\section{EFFICIENCY CHECK}

An efficiency check identifies and evaluates possible revamping measures according to the cost-benefit effect. To identify the equipment to be replaced or newly installed, SMS group offers an efficiency check to be made. This special procedure evaluates the effect of new machines on production in relation to the expenditure (Figure 1). Thus, possible measures can be quickly identified and evaluated to the cost-benefit effect.

\begin{tabular}{|c|c|c|c|}
\hline \multicolumn{4}{|c|}{ EFFICIENCY CHECK LIST } \\
\hline Customer: & \multicolumn{3}{|c|}{ Example Steel Works } \\
\hline Type of Line: & \multicolumn{3}{|c|}{ Hot-dip Galvanizing Line } \\
\hline Last complete year of production: & \multicolumn{3}{|c|}{2015} \\
\hline \begin{tabular}{|l|} 
Products and applications: \\
\end{tabular} & \multicolumn{3}{|c|}{ Automotive Sheets exposed/unexposed } \\
\hline General & Value & Dimension & Production reference \\
\hline Annual maintenance stops & & h & number of annual stops \\
\hline Monthly maintenance stops & & h & number of weekly stops \\
\hline Weekly maintenance stops & & h & number of monthly stops \\
\hline Production hours & & h & \\
\hline Production stop hours & & $\mathrm{h}$ & \\
\hline Entry coil material (input) & & $t / a$ & \\
\hline Pickled coils & & $t / a$ & \\
\hline Number of coils & & pcs/a & \\
\hline Reference strip thickness & & $\mathrm{mm}$ & Reference strip width \\
\hline Product mix available & & yes/no & grouped format \\
\hline min. strip width: & & $\mathrm{mm}$ & \\
\hline max. strip width: & & $\mathrm{mm}$ & \\
\hline min. strip thickness: & & $\mathrm{mm}$ & \\
\hline max. strip thickness: & & $\mathrm{mm}$ & \\
\hline roll diameter of bridle & & $\mathrm{mm}$ & bridle roll surface \\
\hline Entry Section & Value & Dimension & Production reference \\
\hline Coil transportation cycle & & sec & from saddle to mandrel \\
\hline Strip tension & & $\mathrm{N} / \mathrm{mm}^{2}$ & at pay-off reel \\
\hline Anti-coil break roll & & yes/no & \\
\hline
\end{tabular}

Figure 1. Excerpt of the efficiency check list. 


\section{EXAMPLES OF SPECIAL STRIP PROCESSING EQUIPMENT}

Some examples of "Special Strip Processing Equipment" are given in the picture below (Figure 2). Some of them will be explained in the following chapters with more details. In general, SMS offers a broad range of "Special Strip Processing Equipment", which covers all kind of equipment for strip processing lines for carbon, stainless and silicon steel as well as aluminum.

Depending on the individual equipment, the main effects of improvement are decreasing operating costs, enhanced capacity, higher quality and a broader product portfolio.
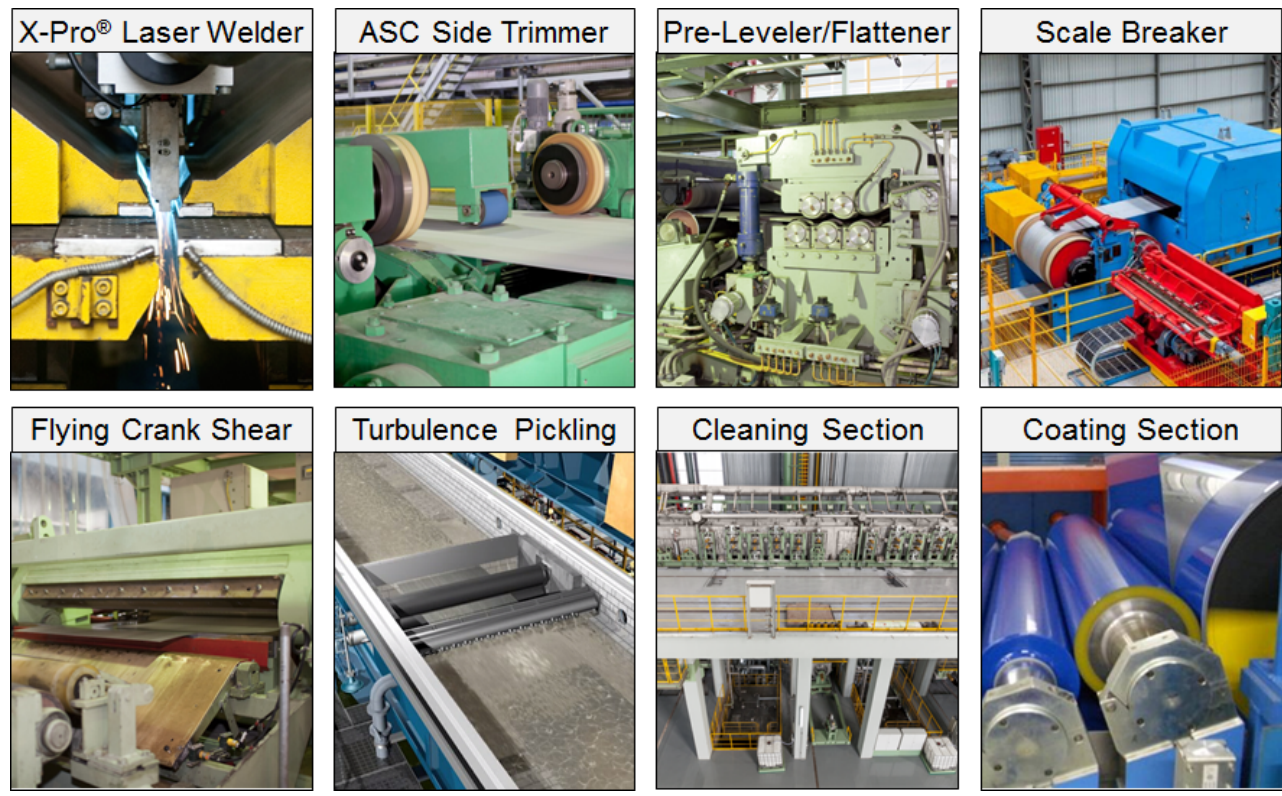

Figure 2. Examples of important "Special Strip Processing Equipment".

\subsection{X-Pro ${ }^{\circledR}$ Laser Welder - Welding of high-carbon steel grades}

An advantage of the welder is the production (inclusive cold-rolling) of difficult-to-weld steel grades on continuous strip processing lines. Therefore, a patented inductive heat treatment of the weld seam for pre- and post-treatment is integrated (Figure 2). It is also possible, to change the post heating start point if necessary (Figure 3 ).

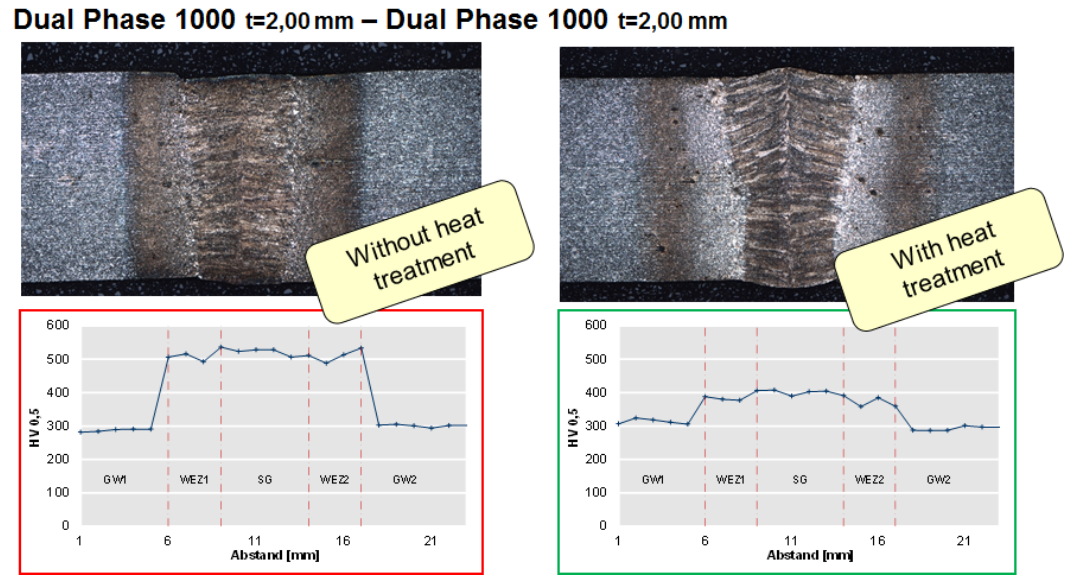

Figure 2. Reduced hardness profile by post heating improves ductility of welded seam. 


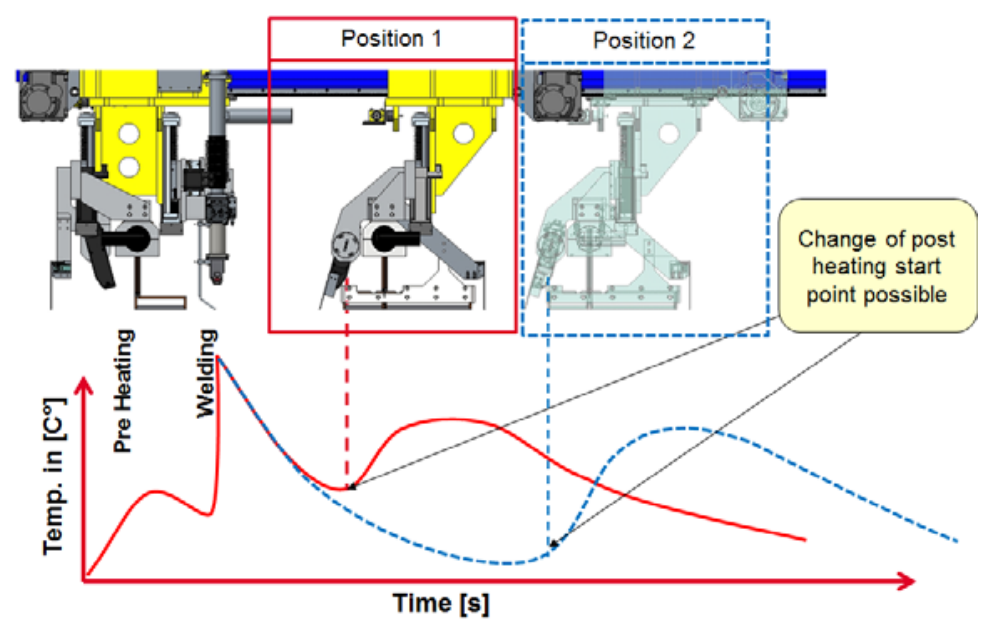

Figure 3. Examples of important "Special Strip Processing Equipment".

Other advantages are the short machine cycle time of less than 60 seconds and a simplified operation with reproducible results. On top of that the welding source can be freely selected. This gives the opportunity to use a conventional $\mathrm{CO}_{2}$ source or a solid state laser source. With a solid state laser it is possible to save process gas (e.g Helium) and reduce the maintenance effort.

\subsubsection{Implementation example}

The X-Pro ${ }^{\circledR}$ laser welder was successfully integrated into the pickling line/tandem cold mill of Hyundai Steel in South Korea. At the Hysco PLTCM martensitic steel grades (MS-W1200) are successfully welded with each other and rolled with high reduction. Furthermore, steels with a silicon content of $1.2 \%$ are welded successfully as well (much higher Si-contents are also possible). (Figure 4). The line has a total capacity of 1.8 Mio. tons per year. The first coil was produced on March $29^{\text {th }}, 2013$, and the final acceptance certificate was awarded to SMS already on June $20^{\text {th }}, 2013$.

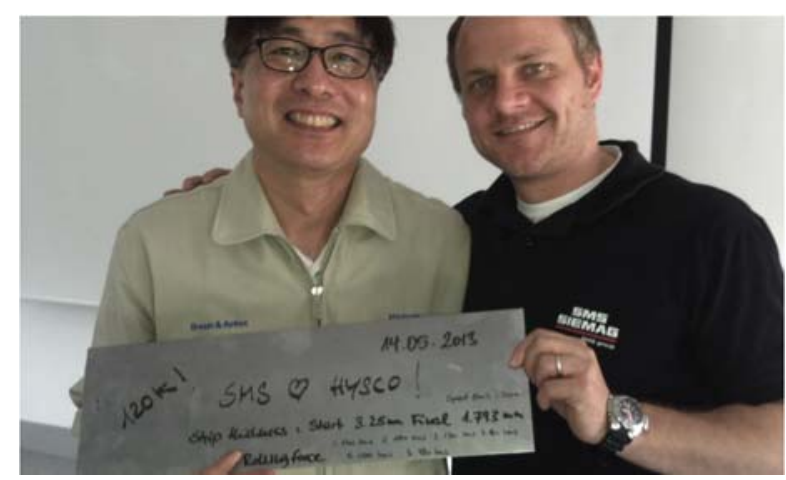

Figure 4. Welded MS1200 rolled with full force and $45 \%$ reduction.

\subsection{Cleaning Section - Innovative technologies to save operating costs}

Due to the high quality demands placed on processed cold strip - especially in the context of car manufacturers' high requirements - the surface quality of the refined sheet needs to be excellent. Even very slight strip impurities can lead to coating faults and impaired quality. That's why it is necessary to remove all impurities such as abraded iron, oil and rolling emulsion residues that occur during cold rolling, transport, and storage before annealing and galvanizing. 
The modern cleaning systems of SMS group usually consist of spray cleaning and electrolytic cleaning; both are followed by brush cleaning and subsequent cascade rinsing processes. The electrolytic cleaning is especially good at removing very fine impurities from the surface. Also some other cleaning technologies (high-pressure, oscillating brushes, etc.) are available which can be installed in existing lines if frame conditions require it.

Due to low evaporation losses, the cleaning units run very energy-efficient. During production, roll changes are possible and oscillating brushes can be used, thus allowing a lowered wear and tear of the brushes. The life expectancy of the brushes can also be improved by smart brush positioning mechanisms, which prevent unnecessary wear and tear. In addition, an intelligent media management system ensures waste water savings and low operation costs.

\subsubsection{Implementation example}

In 2008 SMS modernized the cleaning section of the second hot-dip galvanizing line of Salzgitter Flachstahl $\mathrm{GmbH}$. Several components were removed from the existing cleaning section, and several others were installed, among others, a spray electrolysis, brush machine and rinse cascade. A new exhaust system with 24.000 $\mathrm{m}^{3} / \mathrm{h}$ of power was installed and five new pumps were integrated into the circulation system as well. After a minimal downtime of only 12 days, the plant was up and running again. Due to the taken measures, the cleaning quality was improved and the plants reliability was strongly increased.

\subsection{ASC Side Trimmer - High cutting performance and permanent availability}

In many lines the side trimmer is a bottleneck regarding material strength or reliability. Some lines don't have a side trimmer and can't satisfy some customer demands. The ASC side trimmer (Automatic Setting Control) is available with reliable and proven automation kit equipped with pre-adjusted and pre-installed cutting parameter set-up. The circular blade units are equipped with a combined blade gap setting for the blade overlap and gap. SMS offers various side trimmer configurations and several options for special line requirements (high strength material, thin strips, high speeds etc.) (Figure 5).

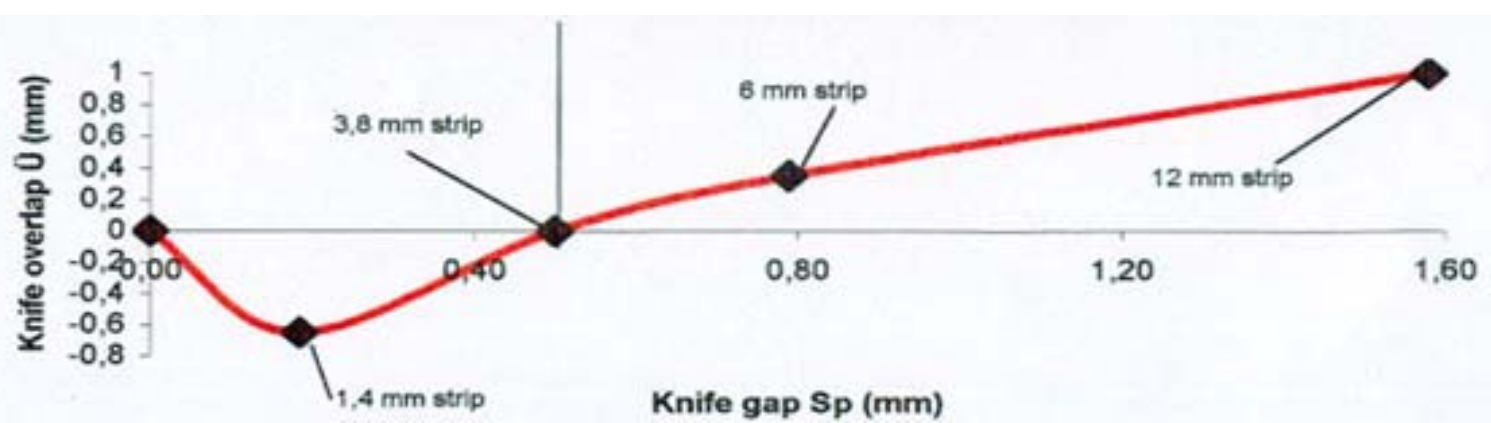

Figure 5. The cutting edge position strongly depends on strip thickness and material (example). .

The integration of an ASC-side trimmer into an existing processing lines or the replacement of an old side trimmer with a powerful new one can lead to various improvements:

- Up to $5 \%$ increased production time

- Extremely low maintenance effort due to cross excenter design and captured bearings at cutting units and choppers (SMS patent) 
- Proven automation kit with pre-adjusted and pre-installed cutting parameter setup

- Quick and easy knife change procedures without any adjustment or fine-tuning

- Face end regrinding of circular knives (easy grinding on flat bed grinder)

$\rightarrow$ Knife gap accuracy after knife regrinding not relying on shims or adjustment procedures

- Seam guiding and scrap chute precise, machined, fitting to constant circular knife diameter (less gaps prevent scrap jams, noise reducing chopper chutes)

- Highest availability with double side trimmer with double chopper

- Precise automatic strip data related knife gap adjustments at trimmer and chopper knives to minimize wear of knives

- Scrap removal systems for every process requirement: scrap chopper, scrap press, scrap baller, combination of chopper and baller, combination of chopper and press

\subsubsection{Implementation example}

SMS group supplied a seven-roller flattener and a side trimmer to Wuppermann Staal in Moerdijk, the Netherlands. The two machines were installed at the entry of hot-dip galvanizing line for hot strip, which has been in operation since 2001. In December 2015, Wuppermann granted SMS the FAC for both machines. The new line configuration at the entry allows Wuppermann to hot-dip galvanize the hot strip face sides and the edges in one pass (Figure 6).

In order to ensure that the sides of the strip are most accurately trimmed, the strip is first leveled in the seven-roller flattening unit. The side trimmer, which is equipped with ASC (Automatic Setting Control), features integrated burr masher and scrap chopper units. SMS group supplied the new special strip processing equipment complete with automation and control systems, facilitating integration into the line and the commissioning process.

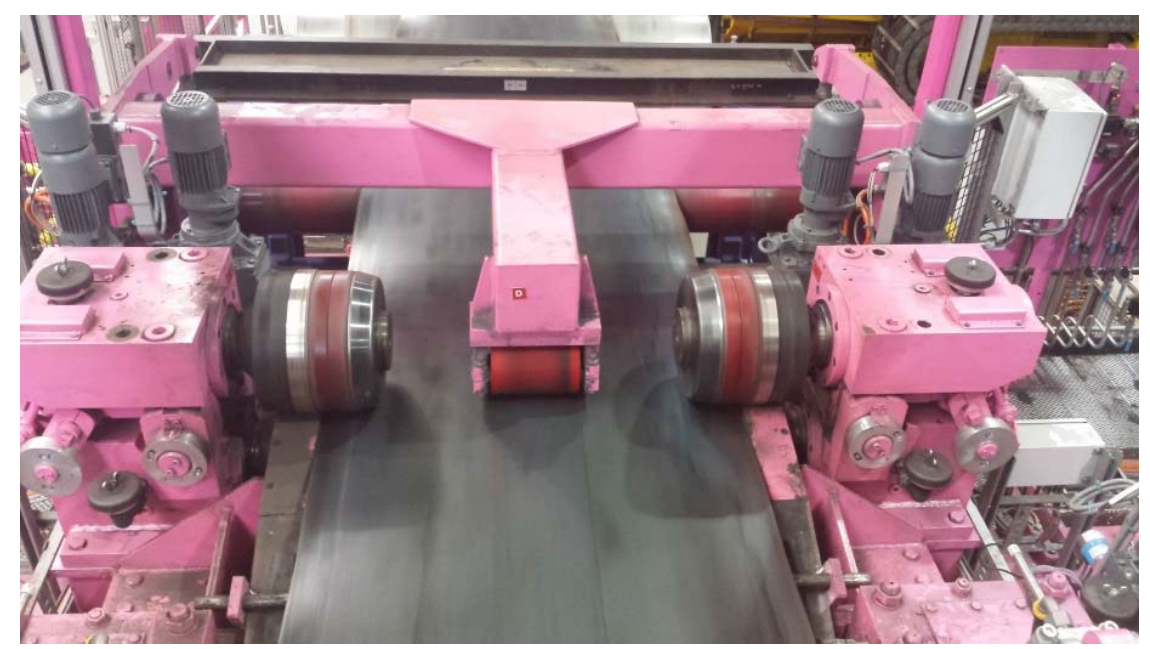

Figure 6. The new side trimming unit installed at the line entry at Wuppermann's galvanizing line.

\subsection{X-Pro ${ }^{\circledR}$ Slitter - Easy adjustment and precise cutting}

The slitting process is very sensible, since various cuts have to be made very accurate and precise at the same time (Figure 7). Therefore, disturbing effects like knife shaft bending have to be avoided and the slitter head has to be manufactured very precise with little tolerances. The production tolerance of the SMS slitter is up to 
2 micron. Most housing surfaces are machined for easy machine calibration. To prevent knife shaft bending it features an extra-long axis knife shaft.

Various features allow an easy and precise adjustment process. Overlapping adjustment is executed via excenters. A big connection axis between excenters ensures a high precision overlap synchronization.

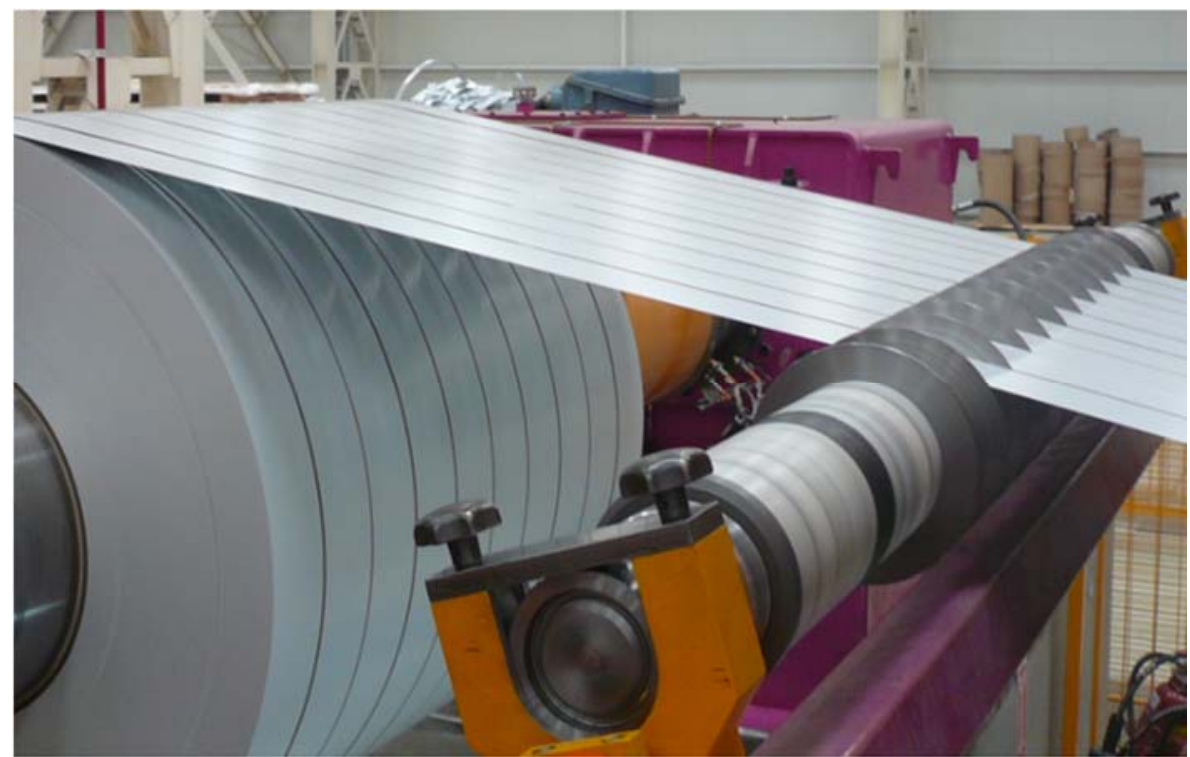

Figure 7. The slitter divides the strip into various small strips.

\subsection{Tension Leveler - Controlled flatness improvement}

Possible out-of-flatness from the rolling process such as waviness or longitudinaland crossbows are eliminated by a tension leveler. The machine is made up of a bending and correcting roller arrangement as well as at least one upstream and downstream bridle roll set to adjust the tension. Different leveling cartridges can be used as required for the material properties and dimensions.

In SMS' tension leveler, the tensioned strip is bent with the smallest possible number of roll contacts. This system protects the strip surface better compared to multi-roller systems (Figure 8). The adjustment positions of the leveling rolls and the required elongation are preset via the level 2 automation. By doing this it is possible to always tune tension and bending in an optimal way to the requirements. Moreover, the elongation is controlled via a closed-loop system to achieve constant elongation along the entire strip length. The bridle rolls are individually driven and a special system prevents possible slipping of the strip on the rolls. The machine can both be operated dry and with minimum quantity lubrication to prevent pick-ups and caking on the strip surface. 


\section{Contact 2}

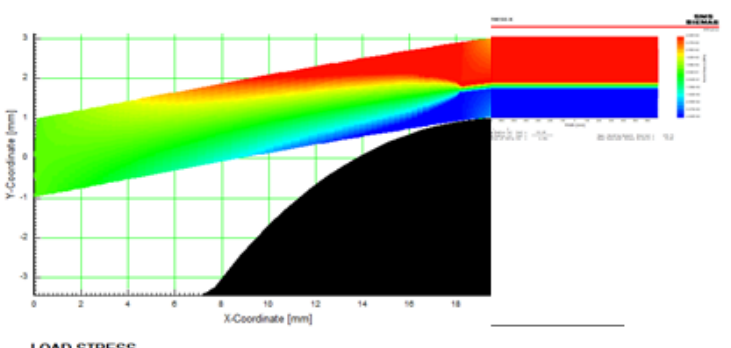

LOAD STRESS

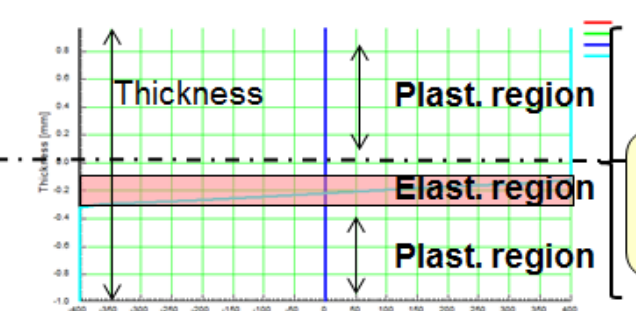

\section{Contact 3}

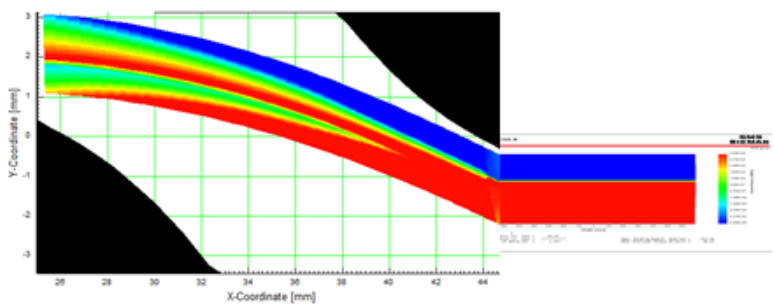

LOAD STRESS

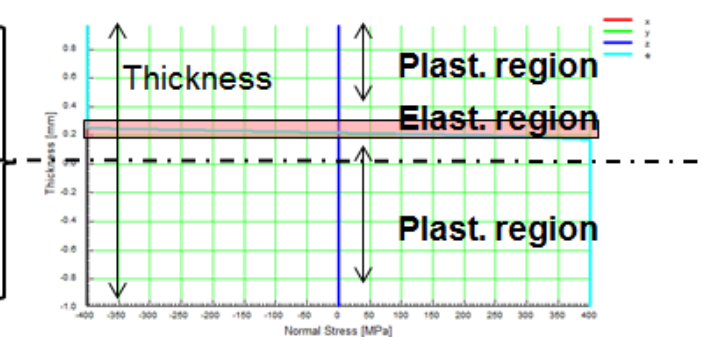

Figure 8. Bending with a tension at $40 \%$ yield strength shows a shift of the elastic region out of geometric center in a way that all cross section areas are stretched

\subsection{Coating Systems - Uniform and high-precision coatings}

Coaters in strip processing lines apply various coatings to the strip surface. SMS offers the whole range of coating technologies. Besides advanced roll coating systems, spray and immersion bath systems complete the product portfolio (Figure 9).

SMS coaters come along with efficient control technology that guarantees a uniform and precise coating result in the required layer thickness at low medium consumption. To achieve the required coating result, a database is linked to the level 2 automation system which provides information for the coating parameters.

\begin{tabular}{|c|c|c|c|c|c|c|}
\hline Name & Principle & Paint & Primer & Passivation & Wax & Glue \\
\hline $\begin{array}{c}\text { Back-up Roll } \\
\text { Coater + }\end{array}$ & & $X$ & $X$ & (X) & - & $X$ \\
\hline $\begin{array}{l}\text { Back-up Roll } \\
\text { Coater }\end{array}$ & & $X$ & $X$ & $(X)$ & - & $X$ \\
\hline $\begin{array}{l}\text { Vertical Roll } \\
\text { Coater }\end{array}$ & & - & - & $X$ & - & - \\
\hline $\begin{array}{l}\text { Horizontal Roll } \\
\text { Coater }\end{array}$ & & (X) & $(X)$ & $X$ & - & (X) \\
\hline $\begin{array}{c}\text { Vertical Roll } \\
\text { Waxer }\end{array}$ & (i) & - & - & - & $X$ & - \\
\hline $\begin{array}{l}\text { Horizontal Spray } \\
\text { Coater }\end{array}$ & 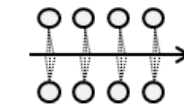 & - & - & $X$ & - & - \\
\hline
\end{tabular}

Figure 9. Overview about various coating principles and applications. 


\subsection{Turbulence Pickling Section - High efficient and economical descaling}

The turbulence pickling section is designed to achieve the highest descaling rate at lowest operation costs.

By injecting hot acid in a flat closed channel an extreme high turbulence at strip surface is created. This turbulence emphasizes a rapid heat and fluid exchange which ensures that the electrochemical potential is built up very fast and the dispersal of the scale layer starts after a few seconds in the pickling channel (Figure 10).

Minimized over-pickling of the strip surface is achieved by an efficient control of the pickling rate by quick adjustment of acid temperature and turbulence.

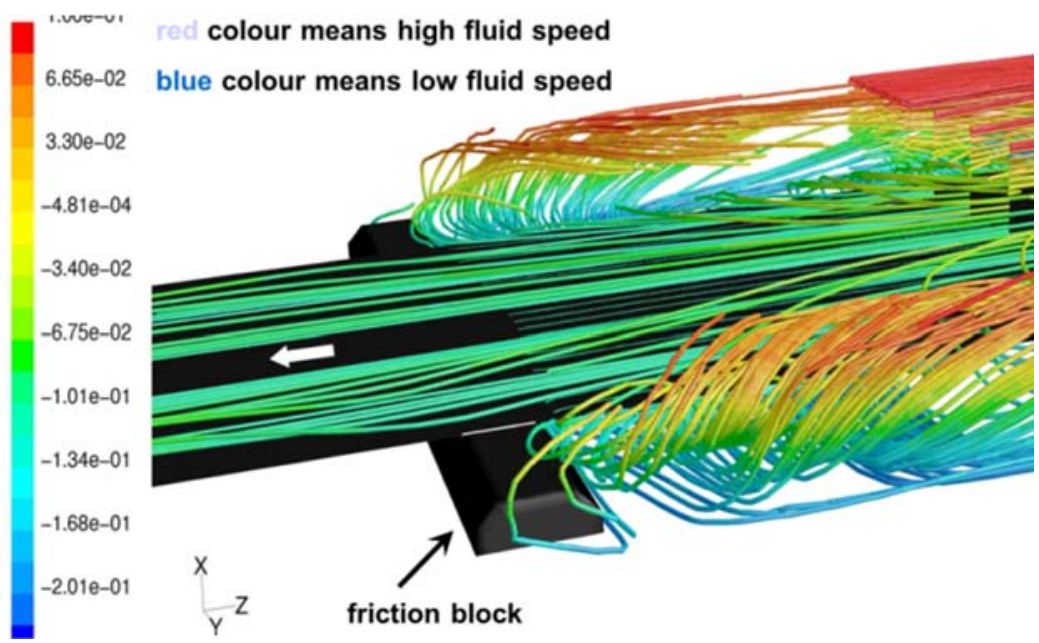

Figure 10. Turbulences cause a high descaling effect due to high heat transfer and acid penetration.

The turbulence pickling system offers various advantages, which can lead to significant benefits for the operators of existing lines after the integration:

- Controlled pickling effect due turbulence and heat control

- Precise strip run due to horizontal strip travel at high strip tension

- Low maintenance costs due to easy tank design and no catenary control

- Reduced energy consumption (sealed pickling channel minimize evaporation loses)

- Optimized operation control by an advanced pickling and production model

\subsection{Spray Boost Pickling Cells - High pickling capacity on a short distance}

With the innovative "Spray Boost Cells", a very high pickling capacity can be achieved on a short distance. Especially for modernizations in the framework of which the pickling capacity is to be increased with only limited space available, this system is an efficient solution. Here, the acid is sprayed onto the strip at high pressure, thus achieving a high pickling capacity. The spray headers patented by SMS ensure a homogeneous distribution of the acid across the entire strip width. Furthermore, the desired pickling capacity can be flexibly adapted.

\subsection{Flying Crank Shear - Fast and continuous cutting during strip run}

The flying crank shear combines fast continuous cutting operation with a reliable and compact design. The design of the shear is based on FEA simulations in order to achieve a perfect cutting result (Figure 11). 


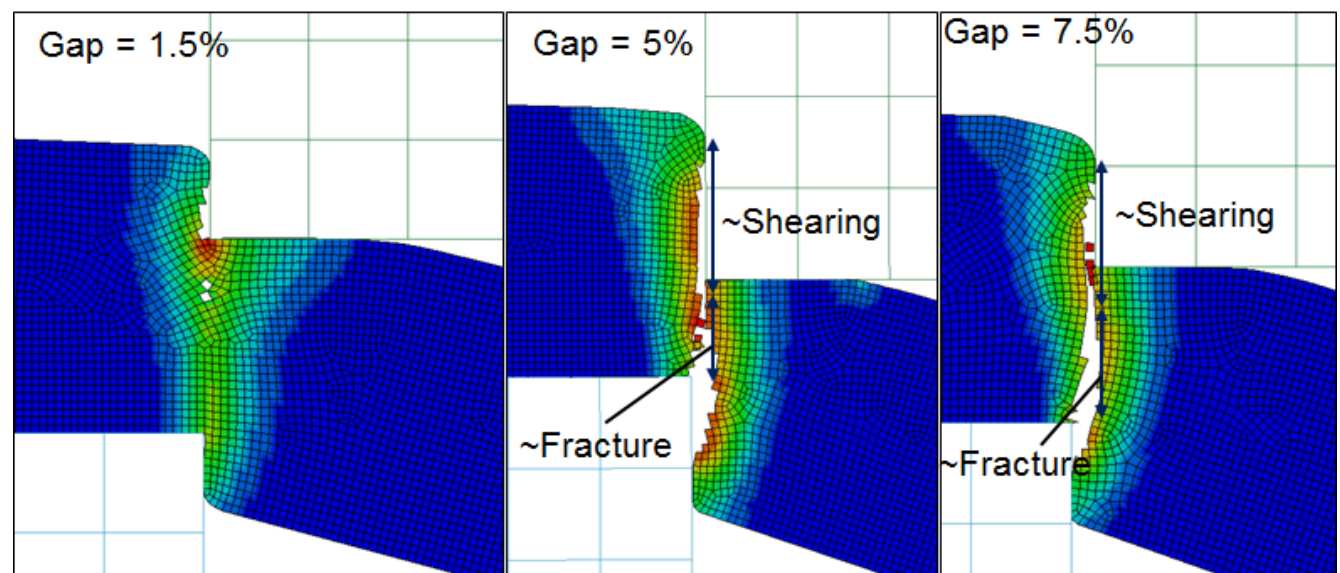

Figure 11. The design of the flying crank shear is based on FEA-Simulations.

The shear is used to cut sheet material or as scrap shear to separate the endless strip into individual coils and to cut out weld seams or defects as well as samples. The length of the sheet products can be selected above base cut-length step less. No risk of drop impurities on the strip surface since the shear is electrically operated no devices containing hydraulic fluid are arranged above strip travel (Table 2).

Table 2. Performance figures of the machine

\begin{tabular}{lc}
\hline Strip thickness & $0.2-12.5 \mathrm{~mm}$ \\
\hline Number of cuts & $>12,000$ \\
\hline Tensile strength & Up to $2,000 \mathrm{MPa}$ \\
\hline Cutting speed & Up to $100 \mathrm{~m} / \mathrm{min}$ \\
\hline Sheet length & $>500 \mathrm{~mm}$ \\
\hline Sample selection & Up to $40 \mathrm{~m} / \mathrm{min}$ \\
\hline
\end{tabular}

\section{CONCLUSION}

The described concept of "Special Strip Processing Equipment" along with the equipment and implementation examples has shown that SMS group is the right partner to keep existing strip processing lines competitive for the future. 